\title{
MANAGEMENT OF FRACTURE SHAFT OF FEMUR IN CHILDREN WITH TITANIUM ELASTIC NAILING (TEN) AT DHAKA MEDICAL COLLEGE HOSPITAL, BANGLADESH
}

\author{
HOSSAIN MM ${ }^{1}$, ALAM QS ${ }^{2}$, HAQUE E ${ }^{3}$, RAHMAN MS ${ }^{4}$
}

\begin{abstract}
Context: Management of femoral diaphyseal fractures in children with ages 5 to 15 years is controversial. There has been debate of operative fixation worldwide.

Objective: To evaluate the outcome of Titanium Elastic Nail (TEN) for the treatment of fracture of shaft of femur in pediatric age group.

Method: Ten children aged 5-15 years with femoral diaphyseal fractures were stabilized with Titanium Elastic Nail (TEN). The results were evaluated using Flynn's Scoring Criteria. Two nails were used in each fracture. Radiological union in all cases was achieved in a mean time of 8 weeks. Full weight bearing was possible in a mean time of 06 weeks.

Result: The results were excellent in 10 patients (100\%). Intramedullary fixation by TEN is an effective treatment of fracture of femur in properly selected patients of the 5-15 years age group.

Conclusion: Treatment of femoral shaft fracture in children aged 5-15years by TEN is ideal, as it hastens fracture union, reduce the rate of mal union, shortening and allow early rehabilitation.
\end{abstract}

Key words: Children, Intramedullary Fixation, Titanium Elastic Nail (TEN), Femoral Fracture, Diaphysis

J Dhaka Med Coll. 2014; 23(1) : 24-30.

\section{Introduction:}

Femoral shaft fracture is an incapacitating injury in children ${ }^{1,2}$. The treatment options are age related, depends on the type of injury, associated injuries and the location and type of fracture. The aim of treatment is anatomical realignment along with restoration of muscle and joint function as close as possible to the normal. Recovery is accelerated by early movement, which encourages healing of fracture, preservation of tone of the muscles and restoration of the movements of the joints. Because of rapid healing and spontaneous correction of angulations most of femoral shaft fractures in children younger than six years of age can be treated conservatively. If age is above six years of age all fractures when treated non-operatively could lead to loss of reduction, malunion, intolerance and complication associated with plaster ${ }^{3,4}$. Near the end of skeletal maturity accurate reduction is necessary as angular deformity is no longer correctable by growth. In skeletally mature adolescents, use of an antegrade solid locked intramedullary nail has be-come the standard of treatment. In patients between 5-15 years of age Titanium Elastic Nailing (TEN) which is variously known as elastic stable intramedullary nailing (ESIN), has become the choice of stabilization in pediatric femoral shaft fracture. The present study is aimed at the evaluation of intramedullay fixation with TEN in children with femoral fractures. Until recently skeletal traction and application of a

1. Dr. Md. Mobarak Hossain, Assistant Professor, Department of Orthopaedic Surgery, Dhaka Medical College Hospital, Dhaka.

2. Dr. Quazi Shahidul Alam, Assistant Registrar, Department of Orthopaedic Surgery, Dhaka Medical College Hospital, Dhaka.

3. Dr. E Haque, Assistant Professor, Department of Spine Surgery, NITOR, Dhaka.

4. Dr. MS Rahman, Registrar, Department of Orthopaedic Surgery, Dhaka Medical College Hospital, Dhaka. Correspondense: Dr. Mobarak Hossain, Assistant Professor Department of Orthopaedic Surgery, Dhaka Medical College Hospital, Dhaka. Cell Phone: +8801715784628, Email. mobarak28@gmail.com 
cast was the preferred method of treatment of diaphyseal femoral fractures in children and young adolescent. Such treatment in children has commonly result in malunion or joint stiffness, limb length discrepancy, delay in functional recovery, psychological, social, educational, economic difficulties. An ideal device would be a single load shearing implant allowing mobilization and maintaining the alignment until bridging callus form without risking the physis or blood supply to femoral head. TEN fulfills that qualities in children aged 5-15 years.

\section{Methods:}

Ten children in the age group of 5-15 years with femoral shaft fracture were stabilized with TEN from January 2013 to May 2014. The predominant mode of injury was due to fall from height (50\%). Right-sided involvement was seen in 6 cases $(60 \%)$ and left side in 4 cases (40\%). Mid-diaphyseal fracture of femur was found in $90 \%$ cases of 10 patients and subtrochanteric fracture in $30 \%$ cases. About $80 \%$ of the patients underwent surgery within 07 days of their injury. The surgery had been carried out in the Department of Orthopaedics, Dhaka Medical College Hospital, Dhaka, Bangladesh. They underwent retrograde intramedullary nailing with a pair of equal size titanium elastic nails. Open, segmental, winquist 3,4 and pathological fracture were excluded.

Nail comes in five diameters from $2.5 \mathrm{~mm}$ to $4.5 \mathrm{~mm}$ in a fixed length. The nails are colour coded for identification. The nails (Figure 1) are straight except for a bent tip. Special instruments include radiolucent reduction tool, nail holder, nail bender, Insertion device, nail ex-tractor, wice grip and a nail impactor were used.

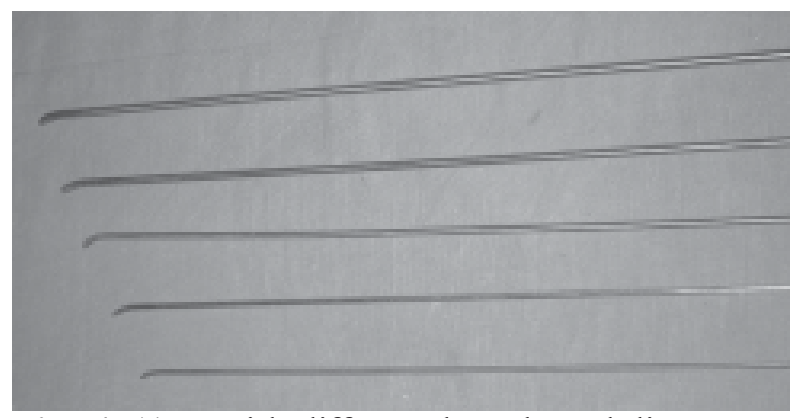

Fig.-1: TEN with different length and diameter.
As soon as anaesthesia was effective, the patient was placed supine on radiolucent fracture table. The limb was prepared and draped to give access to the entire femur and knee joint and to permit manual manipulation of the thigh. The image intensifier was placed so that one could get antero-posterior and lateral view of the femoral shaft.

The selection of the insertion point for the nails was medial and lateral at the top of the flare of the medial and lateral condyles so that after insertion they would tend to bind against the flare of the condyles. In addition, the insertion should be posterior to mid line of the shaft so that if the nails backout, they will be less likely to enter the synovial pouch. A $5 \mathrm{~mm}$ incision was made on the lateral side of the leg extending about two finger breadth above the superior pole of the patella. (The superior pole of the patella lies slightly above the level of the physis). A guide wire for $6.5 \mathrm{~mm}$ cannulated screw was passed at 45 degrees angulation at the level of the superior pole of the patella. Over this a drill hole was made with the cannulated drill bit. Using a curved bone awl, the hole is extended cephalad to elongate the hole and avoid cracking of the cortex when the rod is inserted. The medial entry hole was similarly elongated using a curved bone awl in cephalad direction. The diameter of nail should be $2 / 5$ of the internal diameter of the medullary canal (Nail diameter $=0.4 \times$ Canal diameter). Ideally, the lateral nail should extend to the level of the greater trochanter and the medial nail into the femoral neck. The amount of prebending should be equal for both the nails. (The amount of bending should be three times the inner diameter of the shaft).Both the nails were inserted through the entry holes one after another and were driven upto the fracture site. When the nail was at its final position, it was marked with a pen or clamp about 10 to $20 \mathrm{~mm}$ from the insertion hole. The nails were cut at the marked level and advanced so that they lay against the supracondylar flare of the femur in order to avoid complications at the insertion site. The patients were advised to perform movements at the knee joint and three point touch down exercise the day after surgery. When early callus forma-tion is observed, 
weight bearing can be increased. External support like crutch can be discontinued when radiographic heal-ing is complete. It is important that the patients bear weight because this provides the motion at the fracture site that leads to early callus formation. In all cases post- operative $\mathrm{x}$-rays anteroposterior and lateral views were taken. In the post-operative period parenteral antibiotics were continued for 5 days and then oral antibiotics were given till stitch removal. Along with antibiotics, haematinics, serratiopeptidase, Calcium, multivitamins were given. Stitches were removed on the 14 th postoperative day. After removal of stitch by 13th to 14th day post-operative patients were discharged. Patients underwent regular follow up in the outpatient department for clinical and radiological evaluation.

Around second months after radiograph shows good callus formation. There were no post operative complications.

\section{Results:}

The median duration of the surgery was $80 \mathrm{~min}$ (60-120 min). All 10 patients were available for evaluation All patients were encouraged to do hip and knee non-weight bearing exercises from first post-operative day. Weight bearing was allowed according to the fracture geography and fixation. At the end of 1 st post operative week all patients were made ambulatory on crutches allowing weight bearing according to the quality of fixation. By 8th week all the patients were allowed to bear weight. No broken nails were observed in any of the 10 cases. There were no post operative complications. Leg length inequality, which was about $0.5 \mathrm{~cm}$ present in three patients. Out of 10 patients, malalignment was noted in four patients, five degree varus was found in three while five degree vulgus was present in one patient. No malalignment was found in rest of the six patients. No pain complained at the end of study and more than 130 degree knee flexion was present in all 10 patients. The functional results were assessed according to the criteria of Flynn's scoring system and were excellent. The excellent and successful results were considered as satisfactory. The poor results were considered as unsatisfactory.

Table-I

Flynn's TEN scoring criteria ${ }^{1}$

\begin{tabular}{lccl}
\hline Limb length & $\begin{array}{c}\text { Excellent } \\
<1.0 \mathrm{~cm}\end{array}$ & $\begin{array}{c}\text { Successful } \\
<2.0 \mathrm{~cm}\end{array}$ & $\begin{array}{l}\text { Poor } \\
>2.0 \mathrm{~cm}\end{array}$ \\
\hline discrepancy malalignment $5^{\circ}$ & $10^{\circ}$ & $>10^{\circ}$ \\
Pain & Absent & Absent & Present \\
Complication & Absent & Mild & $\begin{array}{l}\text { Major complication and/ or extended } \\
\text { period for resolvable morbidity }\end{array}$ \\
\hline
\end{tabular}

Table-II

Modified Silvia's scoring

\begin{tabular}{llll}
\hline Score & Shortening & Angle deviations (varus/valgus) & Range of joint movement \\
\hline 0 & Greater than surgery & $>10^{\circ}$ & Flexion $<90^{\circ}$ \\
& /gross shortening & & \\
3 & & $05^{\circ}-10^{\circ}$ & \\
& Existing as previous/ & $<5^{\circ}$ & Flexion up to $90^{\circ}$ \\
5 & shortening present & & \\
& Lower limbs equalization & No deviation & Normal \\
& Grading & Score & \\
& Excellent & 15 & \\
Good & $14-10$ & \\
Fair & $9-7$ & \\
Bad & $<7$ & \\
\hline
\end{tabular}


Table-III

Clinical outcome of the patients under study

\begin{tabular}{lllllllll}
\hline $\begin{array}{l}\text { S1. } \\
\text { No. }\end{array}$ & $\begin{array}{l}\text { Full wt. } \\
\text { bearing }\end{array}$ & Complication & $\begin{array}{l}\text { Leg length } \\
\text { inequality }\end{array}$ & $\begin{array}{l}\text { Malalignment } \\
\text { in degree }\end{array}$ & Pain & $\begin{array}{l}\text { Knee flexion } \\
\text { degree }\end{array}$ & $\begin{array}{l}\text { Activity } \\
\text { level }\end{array}$ & Results \\
\hline 1 & 08 weeks & absent & 0 & 0 & absent & $>130$ & normal & Excellent \\
2 & 07 weeks & absent & 0 & 0 & absent & $>130$ & normal & Excellent \\
3 & 08 weeks & absent & 0 & Varus 5 & absent & $>130$ & normal & Excellent \\
4 & 08 weeks & absent & $0.5 \mathrm{~cm}$ & 0 & absent & $>130$ & normal & Excellent \\
5 & 07 weeks & absent & 0 & 0 & absent & $>130$ & normal & Excellent \\
6 & 08 weeks & absent & 0 & Varus 5 & absent & $>130$ & normal & Excellent \\
7 & 07 weeks & absent & 0 & Valgus 5 & absent & $>130$ & normal & Excellent \\
8 & 08 weeks & absent & $0 \mathrm{~cm}$ & Varus 5 & absent & $>130$ & normal & Excellent \\
9 & 08 weeks & absent & $0.5 \mathrm{~cm}$ & 0 & absent & $>130$ & normal & Excellent \\
10 & 08 weeks & absent & $0.5 \mathrm{~cm}$ & 0 & absent & $>130$ & normal & Excellent \\
\hline
\end{tabular}

Table-IV

Clinical outcome according to Modified Silvia's scoring

\begin{tabular}{lcc}
\hline Sl. No. & Before operation & After operation \\
\hline 1 & 6 & 15 \\
2 & 7 & 15 \\
3 & 7 & 11 \\
4 & 9 & 13 \\
5 & 7 & 15 \\
6 & 6 & 11 \\
7 & 9 & 11 \\
8 & 7 & 11 \\
9 & 7 & 13 \\
10 & 6 & 13 \\
\hline
\end{tabular}

According to modified Silvia's score, final outcome of elastic nailing in this study was $12.80 \pm 1.751$ where 95\% Confidence interval was $11.55-14.05$. Hence, it is $95 \%$ sure that among whole population of femoral diaphyseal fractures in children with ages 5 to 15 years treated by elastic nailing, minimum Silvia's score will be about 11; a 'Good' outcome. There is a significant relationship $(\mathrm{p}<0.05$; Pearson Chi-Square test) between preoperative and Silvia's score after elastic nailing for femoral diaphyseal fractures in children with ages 5 to 15 years.

\section{Case - 1}

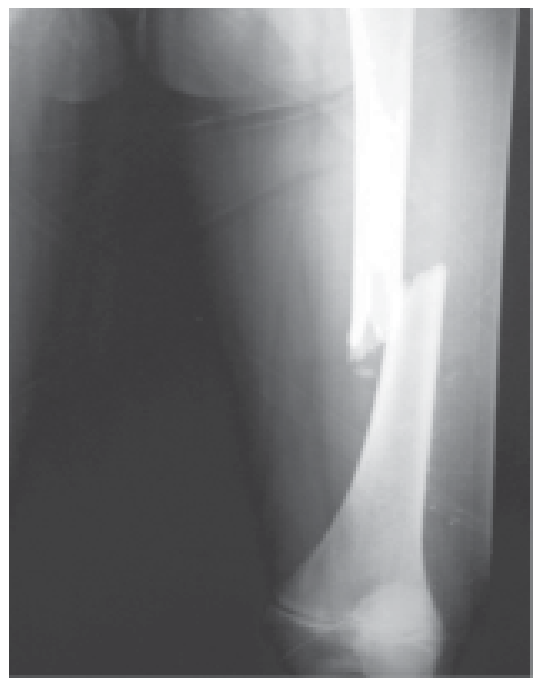

Pre-Operative x-ray on $02 / 01 /$ 2014 (Patient age 8 years)

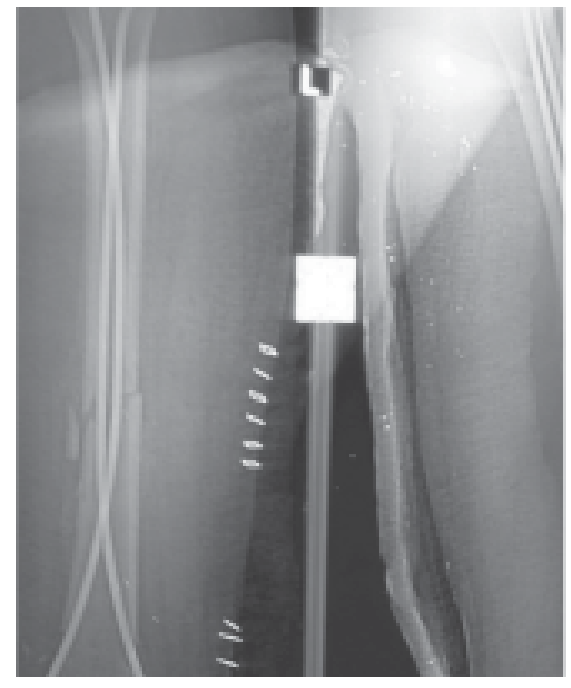

$2^{\text {nd }} P O D$ x-ray on $14 / 01 / 2014$

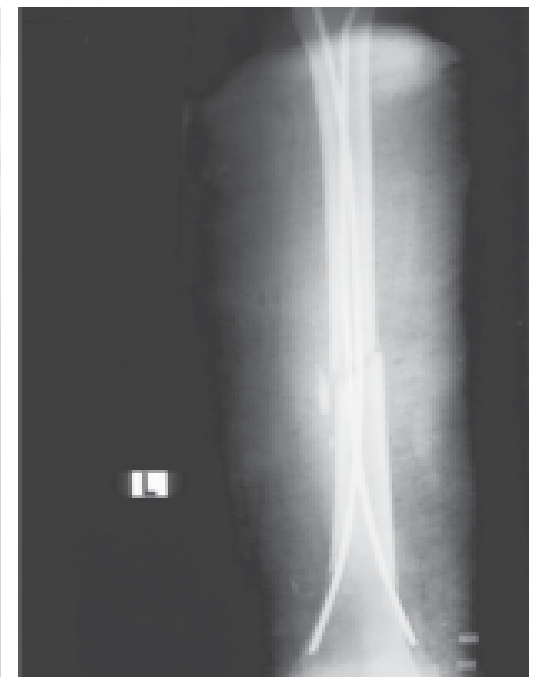

$1^{\text {st }}$ follow up on $27 / 01 / 2014$ 

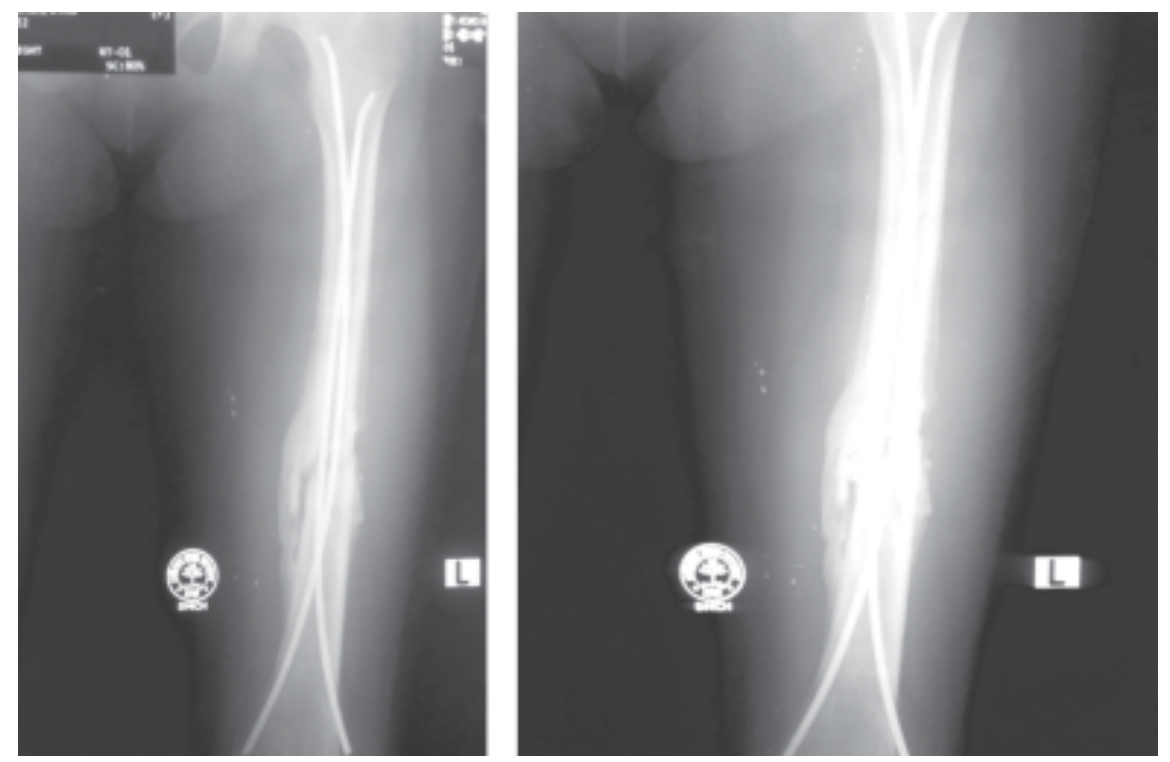

$2^{\text {nd }}$ follow up $x$-ray on $26 / 02 / 2014 \quad 3^{\text {rd }}$ follow up $x$-ray on $26 / 03 / 2014$

\section{Case - 2}

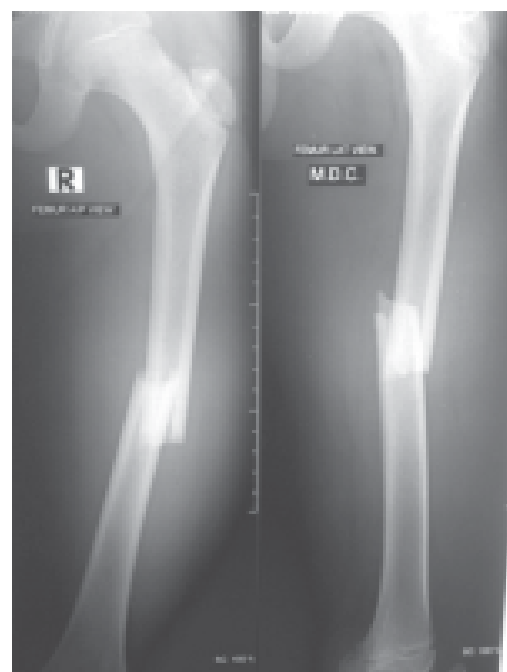

Pre-Operative X-ray on 26/01/ 2014 (Patient age 13 years).

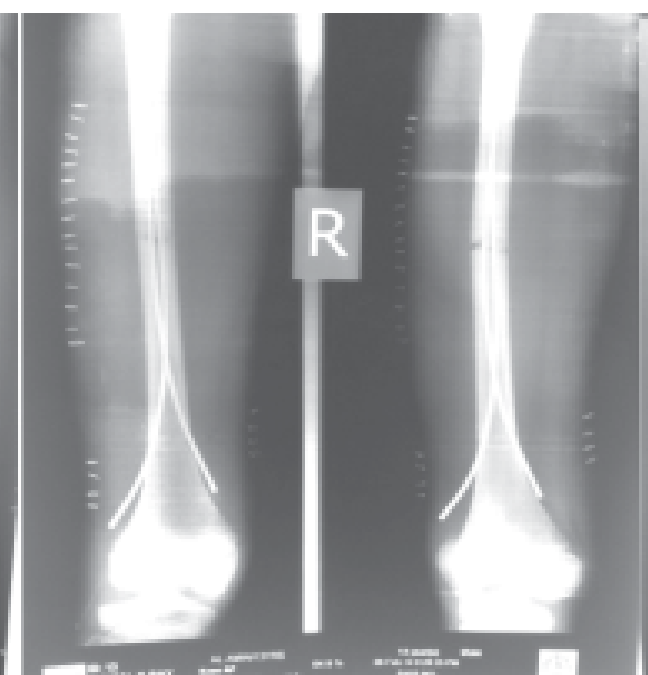

$2^{\text {nd }}$ Post-Operative $x$-ray on 06/02/2014

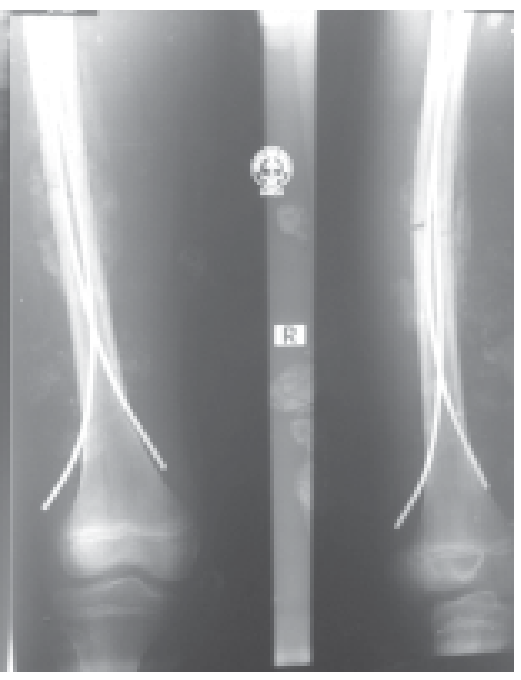

$1^{\text {st }}$ follow up $x$-ray on 17/02/ 2014

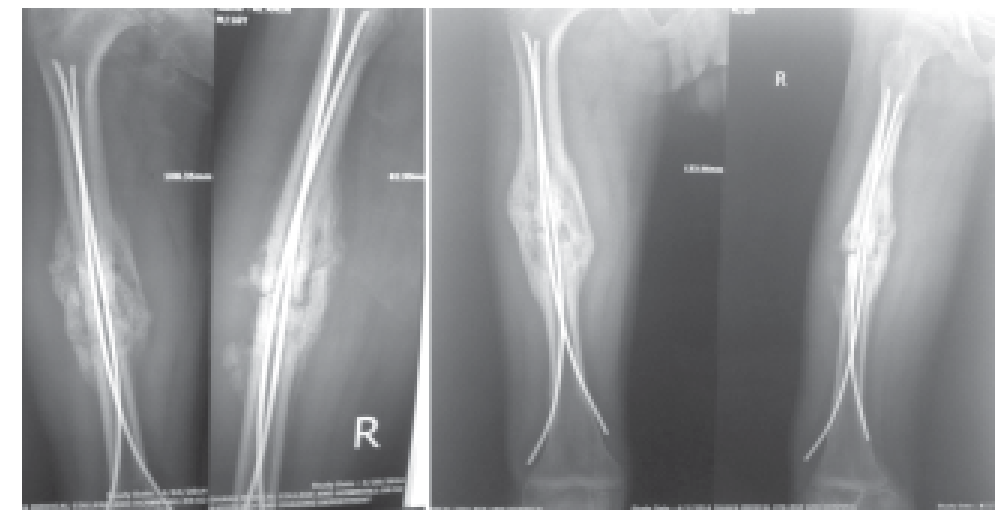

$2^{\text {nd }}$ follow up $x$-ray on 4/4/2014

$3^{\text {rd }}$ follow up 04/05/2014 


\section{Discussion:}

In the present series, TEN was used as a mode of fixation in different types of femoral fractures in children between ages 5 to 15 years. 10 cases were treated and evaluated radiologically, clinically and functionally for the efficacy of TEN. In our series results were excellent in all 10 cases. Heinrich et al. ${ }^{[2]}$ reported that $22 \%$ of their patients had an extension over $5 \mathrm{~mm}$, and $11 \%$ had a shortening under $5 \mathrm{~mm}$. In a study comparing several methods including TEN the maximum shortening was observed in the early casting group followed by external fixator group where as lengthening was observed only in the external fixator group. In our study all cases showed $<1 \mathrm{~cm}$ shortening. Herndon et al. ${ }^{5}$ reported that malunion developed in seven of 24 patients who were treated with traction while no malunion was observed in 21 children who were treated using TEN.

In a study comparing anterograde versus retrograde TEN by Galpin et al. ${ }^{6}$, it was reported that 35 out of 37 patients had excellent improvement in terms of angular deformity. We had angulation less than 05 degree towards varus/valgus or antero/posterior in 10 patients $(100 \%)$. In our series union progressed satisfactorily in all 10 cases. At the end of 8 weeks, 10 cases showed fair to good callus formation. No bone grafting was required in any of the cases. Flynn et al. ${ }^{1}$ found TEN advantageous over hip-spica in treatment of femoral shaft fractures in children. Buechsenschuetz et al. ${ }^{7}$ documented TEN to be superior in terms of union, scar formation and overall patient satisfaction when compared to traction and casting. Ligier et al. ${ }^{8}$ treated 123 femoral shaft fractures with TEN. All fractures united with excellent long term outcome.

All patients were encouraged to do hip and knee non- weight bearing exercises from first postoperative day. At the end of 1 st postoperative week all patients were made ambulatory on crutches, allowing weight bearing according to the quality of fixation.

Flynn et al. ${ }^{1}$ used a knee fixating device to control the pain, to support quadriceps and to prevent the end of nail causing any soft tissue irritation in the knee until the callus tissue appears (4-6 weeks). The patients were able to walk on day 9 on an average with the help of equipment and at week 8.5 on average without the equipment. In our series patients were made ambulatory on crutches after $1 \mathrm{st}$ postoperative week. Partial weight bearing was allowed at 4 weeks and full weight bearing was allowed at 6 weeks.

The results of the present series are comparable to those of the other series on management of femoral shaft fracture in children. It has definite advantages over the other conventional implants that have been used in the management of pediatric fractures. Notable advantages of this technique are early union due to repeated micro-motion at fracture site, early mobilization, early weight bearing, scar acceptance, easy manipulation involved in implant removal and high patient satisfaction rate. Besides these, unlike other implants TEN does not endanger either the epiphysis or the blood supply to femoral head. The excellent biocompatibility and elasticity of titanium have further enhanced the virtues of TEN. High grade of elasticity of titanium limits the degree and permanence of deformation that the nail undergoes during insertion. More importantly elasticity promotes callus formation by limiting stress shielding.

\section{Conclusion:}

It can be concluded that treatment of femoral shaft fracture in children aged 5-15years by Titanium Elastic Nailing (TEN) is ideal, as it hastens fracture union, reduce the rate of mal union, shortening and allow early rehabilitation.

\section{References:}

1. Flynn JM, Skaggs D, Sponseller PD, Ganley TJ, Kay RM, Leitch KK. The operative management of pediatric fractures of the lower extremity. J Bone Joint Surg 2002; 84(12): 2288-2300.

2. Heinrich M, Muratli HH, Celeb L, Gulcek S, Bicimoglu A. The results of intramedullary fixation with titanium elastic nails in children with femoral fracture. Acta Orthop Traumatol Turc 2004; 38(3): 178-187. 
3. Buckley SL. Current trends in the treatment of femoral shaft fractures in children and adolescents. Clin Orthop 1997; 338: 60-73.

4. Kasser JR, Beaty JH. Femoral Shaft Fractures. In: Beaty $\mathrm{JH}$, Kasser JR, eds. Reckwood and Wilkins' fracture in children. $5^{\text {th }}$ ed. Philadelphia: Lippincott Williams \& Wilkins; 2001: p.941-80.

5. Herndon JM, Hresko T, Reynolds RA, Blasier RD, Davidson R, Kasser J. Titanium elastic nails for pediatric femur fractures: a multicenter study of early results with analysis of complications. J Pediatric Orthop 2001; 21(1): 4-8.
6. Galpin RD, Willis RB, Sabano N. Intramedullary nailing of pediatric femoral fractures. J Pediatric Orthop 1994; 14: 184-9.

7. Buechsenschuetz KE, Mehlman CT, Shaw KJ, Crawford AH, Immerman FB. Femoral shaft fractures in children: traction and casting versus casting versus elastic stable intramedullary nailing. J Trauma 2002; 53(5): 914-21.

8. Ligier JN, Metaizeau JP, Prevot J, Lascombes P. Elastic stable intramedullary nailing of femoral shaft fractures in children. J Bone Joint Surg 1988; 70(1): 74-7. 